\title{
DIGITALCOMMONS
}

@WAYNESTATE -

Wayne State University

4-1-2010

\section{Parents Describe Finding Income and Resources for Their Medicaid-Eligible Children With Disabilities}

Joanne Riebschleger

Michigan State University

Marya Sosulski

Michigan State University

Angelique Day

Michigan State University, angelique.day@wayne.edu

\section{Recommended Citation}

Riebschleger, J., Sosulski, M. \& Day, A. (2010). Parents describe finding income and resources for their families while caring for Medicaid-eligible children with a chronic illness or disability. Families in Society, 91(1): 16-24. DOI: 10.1606/1044-3894.3949 Available at: http://digitalcommons.wayne.edu/soc_work_pubs/6 


\title{
Parents Describe Finding Income and Resources for Their Medicaid-Eligible Children With Disabilities
}

\author{
Joanne Riebschleger, Marya Sosulski, \& Angelique Day
}

\begin{abstract}
In the U.S. social system, the roles of work and parenthood are often in conflict, and this conflict is especially problematic for parents of children with special needs. This study was designed to give parents an opportunity to describe their experiences in finding income and resources while caring for a Medicaid-eligible child with a chronic illness or disability. Three themes emerged: work and parenting responsibilities constantly intersected; resources for families were often insufficient or unavailable; and when parents received help, the helpers took extraordinary measures. Findings were compared to those of emerging literature; in addition, parents offered many practice and policy suggestions. Ecological and social construction theory frames were supported, including a need for family-focused perspectives.
\end{abstract}

\section{Implications for Practice}

- Parents of a child with CID need flexible work hours with adequate pay and universal health care benefits.

- These families need increased supportive resources, including access to behaviorally trained child care and school programs.

- Service networks can form alliances to deliver family-centered care as part of a holistic health approach.

\section{Background and Significance}

$\mathbf{T}$ his study explores parents' descriptions of working and providing care for a Medicaid-eligible child with a chronic illness or disability (CID) and the challenges they face. For example, a parent must maintain work attendance and productivity while also taking care of a child's ongoing daytime doctor appointments and school meetings, as well as physical, behavioral, and emotional health crises. Further, the intersection of work and parenting takes place in a social system or structures that rarely provide adequate resources for children with physical, behavioral, or developmental health challenges. So how do parents of a Medicaid-eligible child with a CID describe their experiences in finding sufficient income and resources to take care of their families? In this study, parents share their experiences in response to this research question.

\section{Parenting a Child With a Chronic Illness or Disability}

Over 2 million American children ages 5-17 suffer from a CID (Powers, 2001; Waldrop \& Stern, 2000). A CID can be a serious and enduring physical illness, emotional disturbance, or developmental disability (Zola, 1989). A physical illness is defined as a nonpsychiatric medical diagnosis, such as asthma, arthritis, diabetes, or chronic pain, with at least 1 year of episodic, recurring symptoms that impair the ability of the person to attain optimal functioning. Children with serious emotional disturbances (SEDs) demonstrate difficulties with thinking, affect, and behaviors that interfere with daily functioning in home, school, and the community within the last year. SEDs are consistent with the diagnostic criteria of the Diagnostic and Statistical Manual of Mental Disorders (DSM-IV; 2004) and the Michigan Mental Health Code (1974), and may include oppositional defiant disorder, attention deficit hyperactivity disorder, and separation anxiety disorder (American Psychiatric Association, 2004). A developmental disability is a permanent disability attributable to a mental or physical impairment that manifests before the individual attains age 22 and is likely to require lifelong support. A child with a developmental disability experiences substantial functional limitations in self-care, language, learning, mobility, selfdirection, independent living, and economic self-sufficiency (Ohio Legal Rights Service, 2006).

Children with CIDs demonstrate functional limitations that often require parents to devote extra resources and time to help their children (Hogan, Call, Rogers, \& Avery, 1997). The term parent includes any person legally responsible for the care of a minor child (birth through 17) within a home setting. Family members of children with CIDs report increased direct expenses for child care, specialty health care, medical supplies, medications, adaptive equipment, and hospitalization (Brennan, Rosenzweig, Ogilvie, Wuest, \& Shindo, 2007; Luckmeyer, Meyers, 
\& Smeeding, 2000). Parents are likely to devote time to their children's daytime health appointments, transportation to health care specialists, school meetings, and activities of daily living.

Parents are responsible for the care of their children with a CID, but the parents may themselves also be living with acute or chronic illnesses (Iversen \& Armstrong, 2007). Since parents are also responsible for finding sufficient income and resources for taking care of their families, work and parenting tasks need to be integrated. Sufficient income is defined as having enough financial resources to meet basic family needs (i.e., housing, food, clothing, child care, health care, education, and transportation). Resources are defined as nonemployment derived sources of income, housing, food, clothing, health care, education, and transportation.

\section{Sufficient Income and Resources for Families}

Income earned through paid employment is a critical component of finding sufficient family income and resources. Care for a child with special needs affects employment availability, particularly for single mothers (Brandon \& Hogan, 2004; Gottlieb, 1997; Powers, 2001). Corman, Reichman, and Noonan (2004) found that mothers of children with poor health were less likely to be working than mothers of well children; those mothers who were working reported fewer hours of work per week. As the severity of a child's health condition or the number of children with CIDs in the family increased, the less likely a mother was to be working full time (Porterfield, 2002). Women are more likely then men to have lower-paying jobs without health care, sick leave, and vacation benefits (Heymann \& Earle, 1999). Moreover, women's caregiving responsibilities are not recognized as "work" within the traditional U.S. economy and social welfare system (Arno, Levine, \& Memmott, 1999; Miranne, 1998). Employment is particularly challenging for single women caring for children with a CID (Brandon \& Hogan, 2004; Heymann \& Earle, 1999; Powers, 2001).

Work is a critical part of providing income and resources for taking care of families (Park, Turnbull, \& Turnbull, 2002; Seefeldt, 2004), but there are competing parental caregiving responsibilities that seem especially difficult for poor families to manage (Brennan et al., 2007). Mothers leaving welfare reported encountering employment barriers, including being single parents, coping with their own health conditions, and having little support in the areas of health care, transportation, child care, social support, and education (Hagen, 1999; Taylor, 2001; Zaslow, Hair, \& Dion, 2001). Lack of health care benefits for low-income parents of children with CIDs seriously constrains family economic self-sufficiency (Anderson \& Eamon, 2004). Even one episode of child illness can be problematic, and chronic child health conditions create even greater financial constraints (Halpern, 2005). Also, lower full-time employment among parents of children with special needs means that it is less likely that the child or family will have access to employer-sponsored health insurance. Low-income parents cite access to health coverage as a top priority for children and parent caregivers (Heck \& Makuc, 2000; Perry \& Paradise, 2007).

However, health insurance alone does not guarantee adequate access to health services (Luckemeyer et al., 2000). For example, Howell (2004) found inadequate access to behavioral health services even for children served by Medicaid or the State Children's Health Insurance Program (SCHIP). Moreover, access to insurance benefits and health services for children with CIDs takes place within a system of individual health care that is rarely family-centered (Johnson et al., 2003). Family-centered services rarely take place even within well-coordinated, community-based health, education, and human services (Anderson, 2000; Briggs, Briggs, \& Leary, 2005).

A healthy parent with a supportive social structure is more likely to be able to balance work and caregiving. Rosenzweig, Brennan, and
Ogilvie (2002) studied parents of children with emotional and behavioral disorders and found that they overcame "formidable challenges" in balancing family and work responsibilities (p. 416). Parents said they had difficulty finding flexible work settings that helped them meet their parental responsibilities; some took "lesser jobs" in order to obtain a flexible schedule. Parental work interruptions were frequent, community resources were inadequate, and health and human services were not family-focused (Rosenzweig et al., 2002). Iversen and Armstrong (2007) declared that children's school and work settings brought pressures that endangered parents' job security.

Parents in the Rosenzweig et al. (2002) study emphasized that daycare and school employees were inadequately trained to provide behavioral management and crisis services for their children. In fact, Rosenzweig et al. found that there was a "reliance on families to solve school problems" of the children (p. 420). There are significant social and health costs of under-serving children with CIDs within educational programs (Gresham, 2005; Hodges, Xue, \& Wotring, 2004; Newacheck \& Halfon, 2000). Many educational programs appear to ignore interagency collaboration, caregiver stressors, family needs, individual student counseling, and behavioral management strategies (Anderson, 2000; Kutash \& Duchnowski, 2004; Reddy \& Richardson, 2006; Ross, Blanc, McNeil, Eyberg, \& Hembree-Kigin, 1998; Spilkin \& Ballantyne, 2007). Some emerging educational programs provide intensive health or behavioral management services (DePaepe, Garrison-Kane, \& Doelling, 2002; Evans, Timmins, \& Sibley, 2006; Osher \& Hanley, 2001; Sailor, et al., 2006; Treder et al., 1999). However, many parents continue to report disruptions of their work as a result of unprepared and insufficiently funded educational systems.

Few studies address the integration of a parent caring for a child with a CID, finding work, and sustaining family economic self-sufficiency. Rosenzweig et al. (2002) described how parents' "perceptions about how work and family can successfully fit together have not been systematically studied" (p. 416). The exploratory, descriptive study herein builds on emerging literature about parental work and caregiving in families with a child with a CID. It also highlights new areas of focus for future practice and policy research.

\section{Theoretical Framework}

Assumptions and constructs guiding this study are drawn from ecological theories (Bronfenbrenner, 1979; Germain \& Bloom, 1999) and social construction theories (Gergen, 1985; Robbins, Chatterjee, Canda, Richardson, \& Franklin, 1998). An ecological framework accounts for the interactions of individual and social forces that mutually shape each other; individuals and families adapt to changing social environments in order to survive and grow. Thus parents of children with CIDs adapt to resources and changes in the family, the work setting, and the greater social world.

A social construction framework postulates that people construct multiple realities of the world that are processed internally and assimilated from views passed on by others. Language and customs vary but also become institutionalized within interactions of the social structure. Concepts such as illness and disability are negative social constructions linking to lower social status and less access to structural resources and supports (Jones, 1996; Sontag, 2001). Parents of children with CIDs assimilate socially constructed expectations that they must be productive workers and excellent caregivers of children with special needs despite limited structural supports. Health and human services providers can use a social empathy lens to focus on interactions among 
parents with children with CIDs and the socially constructed systems that influence and surround families (Segal, 2007). They may advocate for more positive and "human constructions" of families of children living with CIDs amidst social structures (Bogdan \& Taylor, 1989). Empathetic and humane perspectives could lead to increased structural resources that are supportive of parents' efforts to find sufficient family income and resources.

\section{Methods}

Researchers asked two focus groups of parents of children with CIDs to respond to the primary research question, "How would you describe your experiences with finding sufficient income and resources to take care of your family?" For inclusion in the study, parents had to have a child with a CID who received Medicaid services (Medicaid-eligible) within 2 years prior to their participation in the focus group. Parents of the children described their parenting experiences while under economic and employment stress. Participants described their experiences and reflected on the meaning of those experiences (Cohen \& Omery, 1994; van Manen, 1990). Focus group facilitators also asked subquestions about participants' experiences with employment, structural supports, and recommendations for policy and services. Examples were:

1. How do physical and behavioral health issues affect your family?

2. What are your experiences with finding and keeping jobs?

3. What are your experiences with Medicaid and other public and private programs?

4. If you could talk to the people who make the rules, what would you say to them?

In addition, participants completed a brief demographic survey about household composition, educational levels, health status, work history, and use of community resources.

\section{Participants and Procedures}

Data were drawn from two focus groups of parents caring for children with CIDs $(n=12)$. They were part of a larger study of families of people recently receiving Medicaid services $(N=36)$. In this study, Medicaid-eligible meant that the focus group participants lived with a family member who either was receiving Medicaid services at the time of the focus group or had received Medicaid within 2 years prior to the focus group.

For this study, data were drawn from focus groups of parents of Medicaid-eligible children with CIDs. Researchers recruited parents using flyers and contacts from caseworkers of two private, nonprofit advocacy organizations in central rural and southeast urban Michigan. The agencies specialized in serving parents of children with CIDs. The caseworkers distributed flyers to parent caregivers of children with CIDs who received Medicaid or had received Medicaid within 2 years prior to this study.

Of the 12 focus group participants, 11 were women. The participants ranged in age from 27 to 66 ; the mean age was 40.5 years. Among the women, 2 were African American, 8 were White, and 1 was Latino. All of the women of color were residents of an urban area. The sole male participant was White and a rural resident.

At the time of the interviews, 5 participants were employed full time, 1 was employed part time, and 6 were unemployed. The level of formal education within the group varied widely. One quarter of the sample had achieved an eighth-grade education, finished high school, earned a
GED, or completed some college. One had earned an associate's degree and another had completed a bachelor's degree. One focus group participant was enrolled in college.

Half of the participants received Medicaid, 5 had private employerpaid health insurance, and 1 declined to respond. Seven participants received Food Stamps, 3 had TANF benefits, and 1 received adult Social Security Disability benefits. None of the parent focus group participants received child support, but 5 received tax credits for home heating and 2 received state assistance for child care.

Focus groups enable an efficient data collection method. Several different perspectives provided the opportunity for an in-depth exploration each parent's experiences and ideas. Krueger (1994) recommends the ideal size of a focus group as being 6-10 participants so that the group is "small enough for everyone to have an opportunity to share insights yet large enough to provide diversity of perspectives" (p. 17). Participants formed a temporary community and helped draw information from each other (Hollander, 2004). Data were collected through interactive group discussion and facilitated with open-ended questions and flexible probes. From an ecological, person-in-environment perspective, the questions addressed the intersections of individual experiences and socio-structural influences (e.g., health policy, human services, and advocacy efforts). The questions suggested areas of interest such as parenting, but were intentionally nondirective in order to maximize participants' interactions with each other (Carey, 1994). Near the conclusion of each focus group, the facilitator reviewed field notes with the group and participants provided feedback on this preliminary interpretation, thereby increasing the validity of the findings (Patton, 1990). At the end of the interview, researchers offered participants the opportunity to share additional information by asking questions such as,"What should we have asked you, but didn't?"

The focus group's responses were audiotaped and transcribed verbatim. Participants gave oral consent in response to a promise of anonymity. In fact, no information about participants' identities was ever collected. Each focus group discussion lasted 2 to 3 hours in a private room of an advocacy agency. Each participant received \$15 and refreshments. Following a participatory action research model, brochures and other documents were provided containing information about local services that could assist families living with a child with a CID to increase access to resources, including employment (Dash, 2004).

\section{Analysis}

The focus group transcripts were analyzed as texts; the emphases were the description of the participants' experiences and the meanings they ascribed to them (Orcutt, 1999; van Manen, 1990). The six members of the research team interpreted each written transcript as a group, line by line, until agreement was reached about which statements appeared to be significant or important to the focus group participants. Repetition of ideas and arguments made by the participants indicated importance, both within the context of each focus group interview question and across questions (e.g., returning to previous topics as the facilitator proceeded through the focus group questions).

Significant statements were coded, assembled into themes, and finally compared with the literature to determine the extent to which they coincided with previous research. The analysis of the emergent themes centered on the meanings intended by the participants within their own experiences and contexts. Thus, anchors in the texts that indicated such awareness guided the researchers. For example, the need for specially trained service providers who were effective with children with special needs recurred as a subtheme. Service provider training 
was a concern that emerged in relationship to schools, child care, and the child welfare system.

Connections among the subthemes yielded insight about parents' experiences with trained and untrained services staff, including the meanings that parents ascribed to these experiences, and implications for practice and policy. Similarly, an overarching theme of the relationship between parenting efforts and economic self-sufficiency developed as researchers recognized connections across subthemes of coded data, classified them, created categories (e.g., parenting and employment), and uncovered both explicit and embedded policy and practice implications (Miles \& Huberman, 1994).

\section{Findings}

Focus group participants described their experiences in attempting to find sufficient income and resources to take care of their families. Parents' descriptions were centered around three main themes:

1. Work and parenting responsibilities constantly intersected.

2. Among many structural challenges, resources to take care of families were often insufficient or unavailable.

3. When parents received help, they described helpers taking extraordinary measures.

Within each theme, parents offered numerous policy and practice suggestions.

\section{Theme One: Work and Parenting Responsibilities}

Parents said work and parenting responsibilities intersected, sometimes to the point of collision. Work was described as necessary for survival of the family, but parenting was participants' first priority. They needed to work, but found that parenting children with CIDs interfered with obtaining and maintaining employment; conversely, the demands of work reduced their capacity for caring for their children with special health needs.

One parent described the devastating impact of losing her job when the needs of her child with a CID interfered with work:

I was fired, and in terms of getting fired, I lost my apartment, and I was homeless. I had nowhere to go..... [I had] problems with my daughter, [an] emotional thing...

Parents frequently said that the spillover of work and parenting responsibilities was stressful. For example, one parent said:

It could, they could, the environment can, cause you so much...so much pressure, that you say "that's it. I'm headed for the door"...the pressure...having so much at home or with the kids and then here's work, like, "Don't bring that over here, because you're here to work."

Another parent explained that the health care needs of her children A, T, and R (pseudonyms) affected her employment availability:

Right now I am trying to figure out how I can get back to work. At least [R] has some summer school, so I could work Monday, Tuesday, and Wednesday and Thursday from this time to this time while A and $\mathrm{T}$ are in summer school. You know it is very difficult and then you've got R's rehab doctor in her office on Thursdays, so that cuts Thursdays out, you know it's just like...how do I work?
Several parents said they had to drop out of college to care for their child. Other parents described negative work sanctions for using sick leave for parenting. One described an attempt to use the Family and Medical Leave Act (FMLA) to care for her son: "But when I returned to work, in my evaluation it was commented that I took too much time off for my son. And my son was suicidal at the time and I was a single parent."

Parents strongly emphasized that their children with CIDs needed a good deal of care. Some participants explained that the entire family was often affected by the children's needs and, sometimes, behaviors:

[I'm a] single mom, my kid, 6-year-old son has ADHD. Um, if you take the 6-year-old away from the picture, it's what would be considered a normal situation. Six-year-old comes back into the picture, it's chaotic, it's crazy, everybody's yelling.

The problems were not limited to young children with CIDs; even older children could not be left alone, and could not assist with care of younger children in the home, as this exchange during a focus group illustrates:

T: My older boy, he has to be watched around the clock.

$\mathrm{N}$ : That's true.

C: That's the way D is, I have to watch him around the clock because I can't leave him with my 8-year-old.

In families with older children who do not have such health issues, older children may help care for younger siblings. However, many of these parents were concerned that caring for the children with CIDs was a disadvantage to their other children.

Parents of children with health conditions, particularly SEDs, described disruptions in their work when they were frequently called by school employees to help manage their children's behaviors or to pick up a child who was ill or dismissed. Some said they lost their jobs when they had to leave work regularly to pick up their child from school. Parent caregivers described, with great emotion, experiences with frequent calls from schools about their children's behaviors:

$$
\begin{aligned}
& \text { C: My daughter, every other day I was getting a call through, uh, } \\
& \text { my daughter's, ah, I guess around that time of when her emotional } \\
& \text { breakdowns started. And, I had to keep going to school to her school } \\
& \text { to have...meetings with the social worker and the special ed, um, } \\
& \text { and it just kept going on. } \\
& \text { S: Yeah well...you know [the] school calls, you gotta come right } \\
& \text { now...he's gotta [go] home, the same story, and you gotta go. }
\end{aligned}
$$

In some cases, the parents viewed the schools as hindering their parenting efforts:

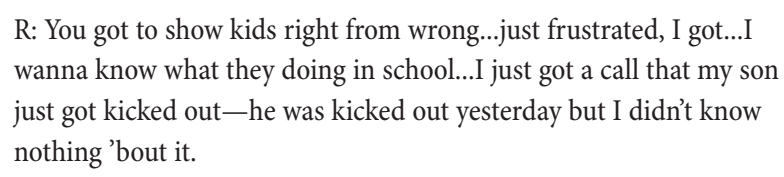
wanna know what they doing in school...I just got a call that my son just got kicked out-he was kicked out yesterday but I didn’t know nothing 'bout it.

Family income. Focus group parents said that demands of parenting a child with a CID often interfered with their efforts to find and maintain employment for attaining sufficient family income. Fewer than half of the parents were employed full time. Parents repeatedly said that they found it difficult to find jobs that accommodated their parenting responsibilities. They gave numerous examples of parent- 
ing challenges that impacted work. The employed parents had clerical positions or worked as services advocates. Four parents were employed as advocates for people with disabilities. One was a full-time foster parent. One was a Work First participant, employed as an administrative assistant. Although researchers did not collect data about household income, the findings seem to indicate that the total household income of participants was relatively low, given parents' descriptions of children's recent Medicaid eligibility. Most of the participants were single mothers with primary parenting responsibilities.

Parents offered many policy and service suggestions. To increase family income, parents recommended increased access to flexible, "family-friendly" employment. Parents appeared to view family-friendly employment as characterized by offering flexible work hours, allowing the parent to bring their children to the work site at times, and allowing the parent to leave the work site for child crises and health care appointments. Some of the participants said they were able to work from their home. One mentioned that parents with a family member with a CID should be able to use the FMLA without it having a negative impact on keeping one's job.

Parents also said they needed "living wage" jobs with benefits such as sick leave and health care. Parents appeared to view a living wage as pay sufficient to meet the basic living needs of their family. They strongly cited a need for access to health care for themselves and their family members, and especially for the child with the CID. They recommended that policies and services facilitate access to child care for teenage youth with a CID.

\section{Theme Two: Insufficient or Unavailable Resources}

Parents said finding sufficient income and resources to take care of their families was difficult within an array of structural challenges including family health issues, financial and time strains, lack of child care, lack of school programs able to deal with behavioral crises, and needs for other community-based resources. Other community-based resources included support for youth transition to adulthood and family-centered, community-based services systems. Within these areas, parents gave examples of insufficient and unavailable resources, as well as recommended policy and service responses.

Family health issues. Resources to meet family health issues were a high priority for the parents. While clearly recognizing limitations, they described Medicaid as being essential to accessing health care services for their child. Some said they worried about families with a child with a CID that did not have health insurance. However, parents also noted gaps in Medicaid coverage with respect to specialty physicians, medications, dental care, and hospital services. They complained that most health care services were available only Monday to Friday during daytime hours. They said this schedule interfered with family needs for work and school attendance. Further, parents adamantly emphasized a need for health care for all family members, including themselves. Many parents said they had their own health care issues. They argued that parents need to be healthy to be able to provide the care needed by children with CIDs and other family members. A parent explained, "I'm a nurse and I take care of...I've adopted kids with disabilities...but I have no health insurance."

Parents viewed behavioral health services as an important part of physical health care. They tended to make connections among physical illness, emotional disturbance, and chronic stress. Parents expressed the need for more funding and programs for behavioral health crises, prevention, and respite services. Especially for crises, parents felt that services were slow and the process for getting approval was burdensome:
C: Like for instance, when my son sliced his wrists, they made him sit in the emergency room and wait for a referral from Medicaid because I took him to [a local hospital] instead of taking him to [a Medicaid, preapproved] hospital. It shouldn't matter whatever area they're in when you got a crisis, it's what the nearest hospital you should be able to take him to. And I don't feel that he should have to wait upon a referral for him to get medical treatment.

Delays in crisis services to children with a SED resulted in exacerbated symptoms, and caused stress for parents:

T: Since we all do have children with special needs...I'm sure that a lot of us get to the point where we wanna break down, where we wanna give up. If you go to a crisis center or a facility in this area... if you have not tried to take your life or anybody else's life, they won't see you. They'll turn you away.

C: Right, well I...I tried to get help before then and I couldn't get it but I had to almost kill myself, one more pill would've killed me.

Mental health parity was an issue raised in the groups, along with more options for day treatment and residential services for children with a SED:

T: What can we do to...have better health care for special needs children? What could we do to make it when they need 30- to 40-day treatment? Can they get that...40-day treatment instead of 5 or 14 ? DC: I wouldn't even put a cap on it.

T: Yeah, right, you know you can't.

DC: If you're in a hospital that has some kind of health problem that had surgery they keep you there, 2 or 3 months...or however long it is. They should do the part of Medicaid-the mental health part of it, parity part that they're trying to pass.

The parents recommended universal health care that is not tied to employment. They said this would allow all family members access to health care. They also recommended expanding the capacity of Medicaid to cover current services gaps. Parents strongly recommended increased access to behavioral health services as part of a holistic health approach, including crisis, respite, and inpatient behavioral health services. They also recommended in-school counseling services for children with CIDs. Essentially, the parents advocated for access to high quality, comprehensive health care for children with CIDs and other family members.

Financial and time constraints. Focus group parents reported numerous financial and time strains to finding sufficient income and resources to care for their families. They noted extra costs incurred for assuring health treatment of the child with the CID, such as copays, transportation to specialty health care providers, and adaptive equipment. They noted that work costs were also a financial strain, including, [car] insurance and gas, and clothing and grooming needs. Parents said it was not fair that family caregiving was not recognized as unpaid labor. They said taking care of children with CIDs required constant effort. They said welfare policy administrators should count family care for a child with a CID as time devoted to hourly workfare requirements.

Child care. Lack of child care was a primary structural barrier to parents' abilities to care for their families. Finding appropriate child care, with workers trained to care for children with severe and persistent health problems, was an overwhelming challenge for the parents: 
S: I have big issues with putting my...I have to say both my kids, but I think I have tendency to lean more towards my daughter. I don't like leaving my kids with people I don’t know. If I do know them and I still...I just have a funny feeling about it, I won’t leave my kids with them.

Parents reported that child care cost so much as to be "almost out of reach" and child care providers were reluctant to accept children with special needs. The issues became particularly complicated when the parents had little economic support to pay for reliable child care and health insurance. Another said:

R: [The children] get sick, the babysitter calls you, you forgot to write down somethin', or your babysitter just doesn't come in that day, you know, it's very difficult. And to work enough hours to maintain insurance, you've gotta pay.

They said child care for the child with the CID was virtually nonexistent and that quality child care providers had no openings, "The good ones are packed." State payment for child care "won't pay the whole thing" and teenagers were not covered. They said some adolescents with a CID still require adult supervision. Per the participants, child care is rarely available for children with short-term illnesses, and it is even less available for children with chronic illnesses. Parents recommended extensive development of accessible, affordable child care with providers trained to deal with physical and behavioral health issues. For example, parents recommended that child care providers develop stronger child behavioral management and crises intervention skills.

Schools. Difficulty finding schools that could manage and care for children with SEDs was a similar structural challenge. Participants reported that children were sent home so often by teachers and administrators that the interruptions interfered with the parents' abilities to maintain employment. Some parents were willing to allow their children to be segregated into separate classrooms for children with extreme health problems, if it would ensure their safety:

C: Um, when you have a child that's suicid[al]....You know the signs that you...you see the signs of them trying to hurt yourself, you go to the school and you let them know to be on the watch for him. 'Cause like I said, my son stabbed himself in school. So, for my other one that I have (pause) mental illnesses, I wanted to let that same school know, that I don't want there to be a second time. I want them to be watched...if you have to exclude them from the other children then do so, but I want them to be watched.

Parents recommended increased behavioral and crisis management skills training for school teachers, aides, and administrators.

Other community-based resources. When parents were asked to discuss any issues that the researchers had not specifically asked about, they said they were concerned about their children's transition to adulthood. Parents said they did not know what would happen when their children "aged out" of Medicaid and other services systems:

DC: And families even if you're living with a child that's 20 to 25 years old, well, he's not a child that time, but...should still have some kinda support for that person, you know.

Parents recommended policy changes that would allow continued Medicaid and other services continuation when children transition from adolescence to adulthood. Parents said that the entire services structure needed to reduce service gaps and fragmentation and to develop structures that were better prepared to meet the needs of children with CIDs and their families. Parents tended to view service structures as a whole. Near the end of one of the focus groups, parent participants nodded in agreement as the facilitator summarized some of the content of the field notes:

[We need a] more flexible work situation, like home care. We talked about ideas for ways that you could pay in to get something that may be not so unreasonable that the insurance would follow the person. We talked about difficulties with the school calling, the kids calling, the babysitter calling, the babysitter not showing up. All these kinds of things.

Parents said that services needed to be available in the community where the family lives. For example, they described situations in which they had to travel great distances to find the specialized care their children needed or to find providers who would accept Medicaid patients, "Basically, provide the services that I need, that my child needs, within my community, in my community, in the palm of my hand."

Parents also cited a need for health, education, and human services organizations and workers to deliver family-oriented models of community care. They defined this as services that would include the entire family and that would include support for parents who must manage multiple demands for work and caregiving: "[We need] family orientated [sic] services...that wherever you go, families, family support...yeah, not just another patient or another number." Therefore, parents recommended development of well-coordinated services structures. They recommended the inclusion of private businesses within the services mix. For example, the parents suggested allowing tax incentives for businesses that provide pro bono services to Medicaid-eligible children with CIDs.

\section{Theme Three: Extraordinary Efforts by Helpers}

The positive experiences of parents attempting to find income and resources for taking care of their families included descriptions of extra efforts of helpers. Some of these helpers included employers, behaviorally focused school programs, competent child care providers, supportive family members, and other community providers. Parent responses about helpers' extraordinary efforts (theme three) were less frequent than the data responses for work and parenting intersection (theme one) and insufficient and unavailable resources (theme two). However, many of the parents wept openly when they talked about professionals who helped them. Parents demonstrated emotional intensity in their descriptions of receiving help; they strongly emphasized how much the help meant to them.

Parents expressed appreciation for several employers who reportedly understood the employee's parenting responsibilities. The employers were described as being flexible in allowing parents to set their own work schedules per the children's needs. One parent described a supportive employer as "family-friendly." Parents said these considerate employers were rare and valuable:

I worked at a place for 4 years and...they allowed my baby to go to work with me. You know just so I could be there to work, other than that I would've been fired, but they worked with me.

Child care providers for children with CIDs were difficult to find. A few parents particularly praised competent and helpful child care workers: 
I found, finally found one...one, um, child care provider that was great, she's a saint, she's wonderful. And she actually got my kids. Every kid in that house was down for a nap at the same time. And you could walk in and any time of the day, just walk in and the kids were playing and they were quiet and they doing activities, coloring, building things, helping her bake cookies.

Most parents in the study did not identify extended family members as a source of extraordinary instrumental or emotional support. However, some parents said that family members helped them find jobs. One parent said her mother was extraordinarily helpful by providing regular child care. Another declared, "My sister is the only one that's ever watched my children." Several parents said they appreciated relatives who regularly listened to them.

Parents valued help from community services workers who went out of their way to listen or to help the parent access resources. Sometimes help came from unusual sources. A single mother with a child with volatile SED behaviors said, "I have [community] cops over [to] my house all the time to check on me." Parents appeared profoundly grateful when describing workers, family, and services providers who engaged in extraordinary efforts to help them.

\section{Discussion and Summary}

Parents' descriptions of finding sufficient income and resources for their families while caring for a child with a CID largely centered on the many challenges they faced in a complex health and human services structure. As they attempted to integrate their socially constructed roles of productive worker and family caregiver, this sample of parents experienced frequent collisions of responsibilities when work and parenting constantly intersected. The caregiving responsibilities for children with CIDs intersected with parents' work so much as to impair parents' abilities to work.

Parents had difficulty finding sufficient community-based resources in an individually focused health, education, and policy network that rarely considered the needs of the family as a whole. Parents reported particular challenges associated with insufficient and unavailable resources to meet family health issues, including a lack of health insurance for parents and other family members, Medicaid service gaps, insufficient access to behavioral health care, insufficient respite care services, and a lack of crisis services. Financial and time constraint challenges aligned with other insufficient or unavailable resources, including unreimbursed special care needs of children with a CID and parent work-related costs, and daytime-only health care services. A strong challenge for parents was the lack of affordable and accessible child care with behaviorally trained providers. Child care for children with CIDs was virtually nonexistent. Parents also declared that few K-12 schools were prepared to provide sufficiently intensive educational programs, with emphases on behavioral management and crisis services. Parents brought up the need for other resources, including supports for youth transitions to adulthood, as well as family-centered, community-based services systems.

Parents' descriptions of their struggle to integrate work and caregiving responsibilities for children with CIDs is supported by other emerging research (Brandon \& Hogan, 2004; Brennan et al., 2007; Rosenzweig et al., 2002). Similarly, other recent research supports parent-identified resource challenges such as family health issues (Anderson \& Eamon, 2004; Perry \& Paradise, 2007; Porterfield, 2002), financial and time constraints (Brennan et al., 2007, Halpern, 2005; Luckemeyer et al., 2000), lack of child care (Porterfield, 2002; Rosenzweig et al., 2002), and unprepared school programs (Evans et al., 2006; Osher \& Handley, 2002; Rosenzweig et al., 2002; Sailor et al., 2006).

Two possibly new findings herein are not as strongly emphasized within the body of literature pertaining to parents of children with CIDs. First, parents worried about their children's abilities to transition to adulthood as they aged out of Medicaid and other services systems. They said the children will not be ready to live on their own at age 18 . Second, when parents reported receiving help, they described helpers taking extraordinary measures. Parents were profoundly appreciative of the rare times they encountered individuals who went out of their way to listen and/or help parents gain resources for taking care of their families. The depth of parent gratitude for extraordinary efforts of individual helpers, including employers, is the emphasis of this finding.

It is important to note that this study has limitations and strengths. The data are drawn from a small, self-selected sample that is largely made up of White women. Since the participants were accessed through advocacy agencies, their experiences may not be typical of most parents that are not directly affiliated with advocacy agencies. It is noted that many of the participants provided data on their experiences within a 2-year time frame, but some data were retrospective. Theme three findings of parents' descriptions of helpers engaging in extraordinary measures were less numerous, albeit emotionally intense. Since many of the parents had a child with Medicaid benefits, the children's health care needs may have been met differently than for those children without health insurance or with private health insurance. However, these are also families that could be expected to have greater access to services because of their connection to the advocacy agencies. This finding should be further investigated to determine what specific selection influences may exist. The self-reported data were not subject to verification.

Descriptive methods fit with the exploratory stage of knowledge development on work and economic self-sufficiency for families with a child with a CID. The rich stories of the parents may enhance the abilities of professionals to understand and prepare to meet family needs, including planning for methods to decrease regular disruptions during the parents' work hours. Near the conclusion of the focus groups, the facilitator checked in with participants about the accuracy of the researchers' interpretations to increase validity. The data analysis procedures were very thorough. To build on these findings, more research is strongly recommended, particularly studies with more rigorous designs and larger, more diverse sampling.

The findings of the study appear to fit well with an ecological theory frame. Parents recommended that planners consider workers, parents, children, families, and those with chronic illness and disability as a whole, and within their social environments. The families needed more support, flexibility, and resources from employers, as well as health, mental health, social services, and educational organizations. Based on the comments of the parents who participated in this study, increasing environmental supports for families living with a person with a CID can increase the parents' abilities to work, support, and care for their children.

Similarly, the study findings align with a social construction theory frame. It appears that families living with a socially constructed "disability" are rendered few resources within the services environment. Parents clearly reported that they were expected by others to be productive workers and excellent child caregivers despite so few supports, and these socially constructive roles literally collided. Indeed, there appeared to be insufficient provider "social empathy" for these struggling parents, children, and families (Segal, 2007). 
Sufficient provider social empathy directed toward families caring for Medicaid-eligible children with a CID could lead policy makers and services providers to consider the needs of caregivers, youth with a CID, and the family as a whole. Within this family-focused frame, a plethora of parent-recommended policy and services changes could be developed or modified. Examples of policies to be developed or modified could include universal health care, incentives for employers that support family-friendly employment, a minimum wage that is sufficient for supporting a family's basic needs, and less frequent practice of school expulsion in cases of children with CIDs. Medicaid changes could include reduced gaps in coverage for special equipment, medication, and transportation needs of the children. Medicaid services could be extended for children with CIDs who manifest significant developmental lags and who are nearing the chronological age of legal adulthood. These changes may help those youths phase into adulthood as their maturity level progresses. Similarly, child care allowance policies should extend coverage for adolescents with CIDs who cannot be left alone. Policy makers should not presume that parents have access to extended family supports.

Examples of community-based services to be developed or modified could include affordable and accessible government-supported child care and school services that offer providers with expertise in managing children's behaviors. Professional education could be enriched by increased curriculum content on behavioral management training for students who will likely be working with children and their families. Health care providers could receive tax incentives for providing afterhours care for parents with children with CIDs. Behavioral health services for children need to be extensively expanded to include more prevention, crisis, respite, outpatient, and sometimes, inpatient services. In-school counseling services could be part of the behavioral health services system. Clearly, there is a need for advocacy of funding increases so as to implement the recommendations herein.

Better coordination between and among community health and human services providers is needed. The array of community-based planners should be thorough and include providers from business, child welfare, courts, law enforcement, behavioral health, public health, churches, and social services. Nonprofit agencies that assist families should be included. The involvement of policymakers, and especially family members, is critical. For example, service providers can learn that an intervention as simple as empathic listening and a little extra effort can result in lasting, positive impressions on family members.

Clearly, it is critical to listen to those directly affected by existing, and needed, policies and services. Miranne (1998) observed, "Policymakers need to turn to the women toward whom...policies are directed. The... experiences should be incorporated into practice and policy directives as they articulate direct family impact" (p. 221). In this study, researchers listened to parents' experiences of finding income and resources for their families while caring for children with CIDs. It is hoped that the findings can be part of a future where parenting and work roles integrate, rather than collide-a future where helping families would not be extraordinary, but routine.

\section{References}

American Psychiatric Association. (2004). Diagnostic and statistical manual for mental disorders (Text revised). Washington, DC: Author.

Anderson, J. A. (2000). The need for interagency collaboration for children with emotional and behavioral disabilities and their families. Families in Society: The Journal of Contemporary Human Services, 81, 484-493.

Anderson, S. G., \& Eamon, M. K. (2004). Health coverage instability for mothers in working families. Social Work, 49, 395-405.
Arno, P. S., Levine, C., \& Memmott, M. M. (1999). The economic value of informal caregiving. Health Affairs, 18, 182-188.

Bogdan, R., \& Taylor, S. J. (1989). Relationships with severely disabled people: The social construction of humanness. Social Problems, 36, 135-148.

Brandon, P. D., \& Hogan, D. P. (2004). Impediments to mothers leaving welfare: The role of maternal and child disability. Population Research and Policy Review, 23, 419-436.

Brennan, E. M., Rosenzweig, J. M., Ogilvie, A. M., Wuest, L., \& Shindo, A. A. (2007). Employed parents with mental health disorders: Achieving workfamily fit, flexibility, and role quality. Families in Society: The Journal of Contemporary Social Services, 88, 115-123.

Briggs, H. E., Briggs, A. C., \& Leary, J. (2005). Family participation in system change. Best Practices in Mental Health, 2(1), 42-58.

Bronfenbrenner, U. (1979). The ecology of human development. Cambridge, MA: Harvard University Press.

Carey, M. A. (1994). The group effect in focus groups: Planning, implementing, and interpreting focus group research. In J. M. Morse (Ed.), Critical issues in qualitative research methods (pp. 225-241). Thousand Oaks, CA: Sage.

Cohen, M. Z., \& Omery, A. (1994). Critical issues in qualitative research methods. Thousand Oaks, CA: Sage.

Corman, H., Reichman, N. E., \& Noonan, K. (2004, May). Mothers' labor supply in fragile families: The role of child health. Ann Arbor, MI: National Poverty Center at the University of Michigan.

Dash, D. P. (2004). Second-order creativity in research: Exploring an action-oriented perspective. In A. K. Geri \& S. N. Eisenstadt, Creative social research: Rethinking theories and methods (pp. 297-307). Oxford, UK: Lexington Books.

DePaepe, P., Garrison-Kane, L., \& Doelling, J. (2002). Supporting students with health needs in schools: An overview of selected health conditions. Focus on Exceptional Children, 35, 1-22.

Evans, S. W., Timmins, B., \& Sibley, M. (2006). Developing coordinated, multimodal, school-based treatment for young adolescents with ADHD. Education and Treatment of Children, 29, 359-378.

Germain, C. B., \& Bloom, M. (1999). Human behavior in the social environment: An ecological view (2nd ed.). New York: Columbia University Press.

Gergen, K. J. (1985). The social constructionist movement in modern psychology. American Psychologist, 40, 266-275.

Gresham, F. M. (2005). Response to intervention: An alternative means of identifying students as emotionally disturbed. Education and Treatment of Children, 28, 328-344

Gottlieb, A. S. (1997). Single mothers of children with developmental disabilities: The impact of multiple roles. Family Relations, 46, 5-12.

Hagen, J. L. (1999). Public welfare and human services: New directions under TANF? Families in Society: The Journal of Contemporary Human Services, 80, 78-90.

Halpern, D. F. (2005). Psychology at the intersection of work and family. American Psychologist, 60, 397-409.

Heck, K. E., \& Makuc, D. M. (2000). Parental employment and health insurance coverage among school-aged children with special health care needs. American Journal of Public Health, 90, 1856-1860.

Heymann, S. J., \& Earle, A. (1999). The impact of welfare reform on parents' ability to care for their children's health. American Journal of Public Health, 89, 502-505.

Hodges, K., Xue, Y., \& Wotring, J. (2004). Outcomes for children with problematic behavior in school and at home served by public mental health. Journal of Emotional and Behavioral Disorders, 12, 109-119.

Hogan, D. P., Call, M. E., Rogers, M. L., \& Avery, R. C. (1997). Improved disability population estimates of functional limitation among American children aged 5-17. Maternal and Child Health Journal, 1, 203-216.

Hollander, J. A. (2004). The social contexts of focus groups. Journal of Contemporary Ethnography, 33, 602-637.

Howell, E. (2004, August). Access to children's mental health services under Medicaid and SCHIP. Washington, DC: Urban Institute.

Iverson, R. R., \& Armstrong, A. L. (2007). Parents' work, depressive symptoms, children, and family economic mobility: What can ethnography tell us? Families in Society: The Journal of Contemporary Social Services, 88, 339-350.

Johnson, H. C., Cournoyer, D. E., Fliri, J., Flynn, M., Grant, A. M., Lant, M., et al. (2003). Are we parent-friendly? Views of parents of children with emotional and behavioral difficulties. Families in Society: The Journal of Contemporary Human Services, 84, 95-108.

Jones, S. R. (1996). Toward inclusive theory: Disability as social construction. NASPA Journal, 33, 347-354.

Kreuger, R. A., (1994). Focus groups (2nd ed.). Thousand Oakes, CA: Sage.

Kutash, K., \& Duchnowski, A. J. (2004). The mental health needs of youth with emotional and behavioral disabilities placed in special education program in urban schools. Journal of Child and Family Studies, 13, 235-248. 
Luckemeyer, A., Meyers, M. K., \& Smeeding, T. (2000). Expensive children in poor families: Out-of-pocket expenditures for the care of disabled and chronically ill children in welfare families. Journal of Marriage and the Family, 62, 399-415.

Michigan Mental Health Code. (1974). Act 258 of 1974. State of Michigan. Retrieved December 31, 2007, from http://www.michigan.gov/documents/ mentalhealthcode_113313_7.pdf

Miles, M., \& Huberman, A. (1994). Qualitative data analysis (2nd ed.). Thousand Oaks, CA: Sage.

Miranne, K. B. (1998). Income packaging as a survival strategy for welfare mothers. Affilia, 13, 211-222.

Newacheck, P. W., \& Halfon, N. (2000). Prevalence, impact, and trends in childhood disability due to asthma. Archives of Pediatric and Adolescent Medicine, 154, 287-293.

Ohio Legal Rights Service. (2006). U.S. Code definition of developmental disability. Retrieved August 25, 2006, from http://www.lbo.state.oh.us/fiscal/budget/ FiscalAnalysis/127GA/LRS.pdf

Orcutt, B. A. (1999). Science and inquiry in social work practice. New York: Columbia University Press.

Osher, D., \& Hanley, T. V. (2001). Implementing the SED National Agenda: Promising programs and policies for children and youth with emotional and behavioral problems. Education and Treatment of Children, 24, 374-403.

Park, J., Turnbull, A. P., \& Turnbull, H. R. (2002). Impact of poverty on quality of life in families of children with disabilities. Exceptional Children, 68(2), 151-170.

Patton, M. Q. (1990). Qualitative evaluation and research methods (2nd ed.). Newbury Park, CA: Sage.

Perry, M., \& Paradise, J. (2007). Enrolling children in Medicaid and SCHIP: Insights from focus groups with low-income parents. Kaiser Commission on Medicaid and the Uninsured. Washington, DC: Kaiser Family Foundation.

Porterfield, S. L. (2002). Work choices of mothers in families with children with disabilities. Journal of Marriage and Family, 64, 972-981.

Powers, E. T. (2001). New estimates of the impact of child disability on maternal employment. The American Economic Review, 91, 135-139.

Reddy, L. A., \& Richardson, L. (2006). School-based prevention and intervention programs for children with emotional disturbance. Education and Treatment of Children, 29, 379-404.

Robbins, S. P., Chatterjee, P., Canda, E. R., Richardson, F., \& Franklin, C. (1998). Phenomenology, social constructionism, and hermeneutics. In S. P. Robbins, P. Chatterjee, \& E. R. Canda (Eds.), Contemporary human behavior theory (pp 295-320). Boston: Allyn \& Bacon.

Rosenzweig, J. M., Brennan, E. M., \& Ogilvie, A. M. (2002). Work-family fit: Voices of parents of children with emotional and behavioral disorders. Social Work, $47,415-424$.

Ross, C. N., Blanc, H. M., McNeil, C. B., Eyberg, S. M., \& Hembree-Kigin, T. L. (1998). Parenting stress in mothers of young children with oppositional defiant disorder and other severe behavior problems. Child Study Journal, $28(2), 93-110$.
Sailor, W., Zuna, N., Choi, J., Thomas, J., McCart, A., \& Blair, R. (2006). Anchoring school-wide positive behavior support in structural school reform. Research and Practice for Persons with Severe Disabilities, 31, 18-30.

Seefeldt, K. S. (2004, Fall). After PRWORA: Barriers to employment, work, and well-being among current and former welfare recipients. Poverty Research Insights. Retrieved May 23, 2005, from http://www.npc.umich.edu/ publications/newsletter/fallo4/1/index.shtml

Segal, E. A. (2007). Social empathy: A tool to address the contradictions of working but still poor. Families in Society: The Journal of Contemporary Social Services, $88,333-338$.

Sontag, S. (2001). Illness as metaphor and AIDS and its metaphors. New York: Picador. Spilkin, A., \& Ballantyne, A. (2007). Behavior in children with a chronic illness: A descriptive study of child characteristics, family adjustment, and school issues in children with cystinosis. Families, Systems, \& Health, 25, 68-84.

Taylor, L. C. (2001). Work attitudes, employment barriers, and mental health symptoms of a sample of rural welfare recipients. American Journal of Community Psychology, 29, 443-463.

Treder, D., Kutash, K., Duchnowski, A. J., Calvanese, P. K., Robbins, V., Oliveira, B., et al. (1999). School and community study: Exemplary school models and student outcomes over time. Annual Research Conference Proceedings of a System of Care for Children's Mental Health: Expanding the Research Base. Washington, DC: Center for Mental Health Services.

van Manen, M. (1990). Researching lived experience. London, Ontario: Althouse. Available from the Center for Health Statistics, Division of Health, Wisconsin Dept. of Health and Family Services.

Waldrop, J., \& Stern, S. M. (2000). Disability status: 2000. Washington, DC: The U.S Census Bureau.

Zaslow, M. J., Hair, E. C., \& Dion, M. R. (2001). Maternal depressive symptoms and low literacy as potential barriers to employment in a sample of families receiving welfare: Are there two-generational implications? Women \& Health, 32, 211-251.

Zola, I. K. (1989). Toward the necessary universalizing of a disability policy. Milbank Quarterly, 67(2:2), 401-428.

Joanne Riebschleger, PhD, LMSW, ACSW, is assistant professor, Marya Sosulski, $\mathrm{PhD}$, LMSW, is assistant professor, and Angelique Day, LMSW, is research specialist, School of Social Work, Michigan State University. Correspondence regarding this article can be sent to the first author at riebsch1@msu.edu or School of Social Work, Michigan State University, 254 Baker Hall, East Lansing, MI 48824.

Manuscript received: January 29, 2008

Revised: October 7, 2008

Accepted: November 11, 2008 